respondents who answered positively to parts (c) and (e) based their decision on age, severity of the illness, and/or the infecting organism.

Of the 504 positive reports of routine referral, $271(53 \cdot 8 \%)$ claimed to refer children immediately on discharge, $230(45.6 \%)$ at the first outpatient appointment, and three $(0.6 \%)$ at some later time. The responses indicate that about $60 \%$ of children are referred within three months and all within a year of discharge.

The majority of the additional comments about postmeningitic hearing impairment $(n=62)$ indicated that cases of hearing impairment were seen very infrequently, eight respondents having never seen a case. Other comments concerned factors possibly associated with hearing impairment $(n=28)$. Some of these were based on misunderstandings of the aetiology. Thirteen respondents stated that hearing impairment only followed infection with Streptococcus pneumoniae or Haemophilus influenzae. At least three doctors thought that the referral was not urgent and one thought that the routine distraction test of hearing at 8 months was a sufficient safety net for children younger than this age.

Comments in 25 cases concerned problems with assessing the children including long waiting lists for audiology, lack of direct access to the audiology service, and the lack of age appropriate testing skills.

\section{Discussion}

The results of this survey are very encouraging. They indicate that, in general, paediatricians are aware of the need for formal hearing assessment and are including this as part of their routine management. It is to be hoped that these good intentions are always translated into good practice.

The results indicate that doctors who say that they do not always refer are basing their decisions most often on a clinical concern over the child's hearing. This implies that paediatricians are acting as the first screen of hearing ability after bacterial meningitis. The accurate bilateral testing of young children is difficult even in the best surroundings and impossible in a busy ward or outpatient clinic. A child who appears to hear in such circumstances may none the less have a mild to moderate bilateral or a unilateral impairment.

Whether age is an appropriate referral criterion must be determined from good quality epidemiological data, but no satisfactory study so far supports the restriction to those under 3 years. This cut off would not reduce the workload of the audiological services by an appreciable amount as the majority of cases occur under this age, but it would mean that some children with damage to their hearing would be missed. ${ }^{6}$

Referral based on the bacterium responsible would also miss some children with hearing impairment as hearing impairments have been found after meningitis due to each of the major infective organisms. ${ }^{6}$

In our view, when to refer postmeningitic children should not be in question. Referral should be made while the child is still in hospital and the importance of the assessment stressed to the parents. The assessment should ideally take place four to six weeks after discharge to allow for resolution of any associated conductive impairment and to ensure that profound hearing impairments are detected early enough to enable a cochlear implant to be a viable option.

Our thanks go to the paediatricians who took the time to answer and return the questionnaire and to Professor Mark Haggard and Dr Adrian Davis for helpful comments.

1 Salwen KM, Viskerfors T, Olcen P. Increased incidence of childhood bacterial meningitis. A 25-year study in a defined population in Sweden. Scand F Infect Dis 1987;19:1-11.

2 Carter PE, Barclay SM, Galloway WH, Cole GF. Changes in bacterial meningitis. Arch Dis Child 1990;65:495-8.

3 de Louvois J, Blackbourn J, Hurley R, Harvey D. Infantile meningitis in England and Wales: a two year study. Arch Dis Child 1991;66:603-7.

4 Brookhouser PE, Auslander MC. Aided auditory thresholds in children with postmeningitic deafness. Laryngoscope 1989;99:800-8.

5 Brookhouser PE, Auslander MC, Meskan ME. The pattern and stability of postmeningitis hearing loss in children. Laryngoscope 1988:98:940-8.

6 Finitzo-Hieber Y, Simhadri R, Hieber JP. Abnormalities of the auditory brainstem response in post-meningitis infants the auditory brainstem response in post-meningitis infants

\title{
Toxic shock-like syndrome caused by adenovirus infection
}

\author{
K Bojang, M D S Walters
}

\begin{abstract}
Adenovirus infections commonly occur in childhood and produce a wide range of clinical disease. The most common sites of infection are the respiratory and gastrointestinal tracts but involvement of cardiovascular, neurological, cutaneous, ophthalmic, renal, and hepatic systems can also occur. A case of toxic shocklike syndrome with symptoms of multiorgan involvement resulting from adenovirus infection is reported.
\end{abstract}

(Arch Dis Child 1992;67:1112-4)

\section{Case report}

Four weeks after returning from a two month holiday in the Philippines and Australia a 5 year old girl developed abdominal pain, fever, and vomiting. Over the subsequent four days she developed an erythematous maculopapular rash on her abdomen, profuse watery diarrhoea, and was admitted to the referring hospital. At the initial examination she had fever, cervical lymphadenopathy, and was dehydrated. She was rehydrated with normal saline and started on flucloxacillin and cefuroxime. Over the next 24 hours her serum sodium concentration

Praed St's Hospital,

London W2 $1 \mathrm{NY}$.

Accepted 6 May 1992 
dropped from 129 to $115 \mathrm{mmol} / \mathrm{l}$ despite good renal function. Her haemoglobin concentration was $11.4 \mathrm{~g} / \mathrm{l}$, white cell count increased from $9 \cdot 3 \times 10^{9} / 1$ to $19 \cdot 1 \times 10^{9} / 1$, and her platelet count fell to $93 \times 10^{9} / 1$. Her tissue perfusion deteriorated and metabolic acidosis developed requiring circulatory support with dobutamine and colloids. She was referred to the intensive care unit, Hospital for Sick Children, Great Ormond Street, for further management.

On arrival she was febrile with a temperature of $39.5^{\circ} \mathrm{C}$. She had an erythematous rash over her trunk with target lesions similar to erythema multiforme, erythematous palms, fissured lips, and conjunctivitis. She was tachycardic and hypotensive (pulse 150/minute, systolic blood pressure $70 \mathrm{~mm} \mathrm{Hg}$ ) and had a cold periphery. She had peripheral oedema in her lower limbs and over her sacrum. She was breathing spontaneously in $50 \%$ oxygen with marked respiratory distress. On auscultation there were widespread crepitations in both lung fields. Her abdomen was distended and tender. She was disorientated and restless.

\section{INVESTIGATIONS}

Results of laboratory investigations are shown in the table. A chest radiograph showed cardiomegaly and pulmonary oedema. Her electrocardiogram was normal and an echocardiogram showed an enlarged poorly functioning left ventricle but no intracardiac structural abnormality.

Blood cultures taken before antibiotics were started were negative. An initial sample of cerebrospinal fluid contained a white cell count of $3 / \mathrm{mm}^{3}$, protein concentration $0.33 \mathrm{~g} / \mathrm{l}$, and glucose $4.8 \mathrm{mmol} / \mathrm{l}$. No organisms were seen and there was no growth on primary culture. Routine cutaneous swabs grew no pathogens and a malaria parasite slide was negative. Antistreptolysin-O titre was 100 Todd units and anti-DNAase titre 100 units.

In view of the fact that she had spent two months in the Philippines and Australia, serological testing for geographically relevant pathogens (including arboviruses) was performed and found to be negative.

PROGRESS

The clinical picture was compatible with a

Results of laboratory investigations

\begin{tabular}{lc}
\hline Investigation & Result \\
\hline Haematology: & $7 \cdot 9$ \\
Haemoglobin $(\mathrm{g} / \mathrm{l})$ & $13 \cdot 5$ (neutrophils $11 \cdot 4)$ \\
White cell count $\left(\times 10^{9} / \mathrm{l}\right)$ & 79 \\
Platelet count $\left(\times 10^{9} / \mathrm{l}\right)$ & \\
Biochemistry: & 127 \\
Sodium (mmol/l) & $2 \cdot 8$ \\
Potassium (mmol/l) & $9 \cdot 5$ \\
Urea (mmol/l) & 80 \\
Creatinine $(\mu \mathrm{mol} / \mathrm{l})$ & $1 \cdot 68$ \\
Calcium (mmol/) & \\
Liver function tests: & 18 \\
Albumin (g/l) & 28 \\
Total bilirubin $(\mu \mathrm{mol} / \mathrm{l})$ & 104 \\
Aspartate aminotransferase (U/l) & 8130 \\
Creatine phosphokinase (U/l) & \\
\hline
\end{tabular}

diagnosis of staphylococcal toxic shock syndrome. She required ventilatory support and suffered from severe hypotension and cardiac insufficiency requiring high dose dobutamine and dopamine to maintain her blood pressure. This high dose inotropic support was needed for three days, but as her cardiac function began to normalise support was able to be gradually reduced over the next four days. She was unconcious for three days with an electroencephalogram showing non-specific features of diffuse encephalopathy. It was thought that this was due partly to her underlying disease but also partly due to increased opiate sensitivity. A cranial computed tomogram was normal. Initially she had considerable abdominal distension, pain, and diarrhoea, and this gradually resolved over the next week. Nine days after admission she was extubated and all inotropic support discontinued. After a further two days she developed desquamation over the tips of all her fingers. She continued to improve and was discharged after 17 days in hospital with a diagnosis of staphylococcal toxic shock syndrome.

However, after discharge a non-typable strain of adenovirus was isolated from culture of both the cerebrospinal fluid and urine specimens collected at her original presentation. Follow up serology demonstrated a rising CF titre of antibody to adenovirus from initially undetectable on admission, to $1: 16$ one month later and to $1: 32$ six weeks later. Immune function tests during convalescence showed raised serum $\operatorname{IgG}_{1}$ $(20 \mathrm{~g} / \mathrm{l}$, normal $3 \cdot 2-7 \cdot 6 \mathrm{~g} / \mathrm{l})$ and $\operatorname{IgM}(4 \cdot 9 \mathrm{~g} / \mathrm{l})$, suggesting a recent infection, and normal serum $\mathrm{IgG}_{2}, \mathrm{IgG}_{3}, \mathrm{IgG}_{4} \operatorname{IgA}, \mathrm{IgE}$, complement, and normal $T$ cell subsets and lymphocyte PHA responses. There was therefore no evidence of immunodeficiency.

\section{Discussion}

The toxic shock syndrome is a clinical diagnosis based on case definition. ${ }^{1}$ There is no confirmatory laboratory test and the isolation of TSST-1 producing Staphylococcus aureus is not required to establish the diagnosis. Our patient satisfied the clinical diagnostic criteria for toxic shock syndrome in that she had fever $38.9^{\circ} \mathrm{C}$, an erythematous rash, desquamation, and hypotension. She had additional involvement of the following organs and systems: central nervous system, gastrointestinal tract, skeletal muscle, heart, respiratory tract, liver, and her haematological system. She also had initial negative microbiological results to establish an alternative diagnosis. However, the subsequent growth of adenovirus from her cerebrospinal fluid and urine and her seroconversion confirmed disseminated adenovirus infection.

Adenovirus infection can involve many organ systems, but the respiratory and gastrointestinal tracts and conjunctiva are most frequently involved. The skin, heart, central nervous system, skeletal muscles, liver, and kidneys are occasionally involved. ${ }^{2}$ It is, however, very uncommon for a single adenovirus strain to produce multisystem disease in an apparently immunocompetent individual. This case had 
multisystem involvement, some of which may be explained by the effects of shock, but the skin changes, the central nervous system involvement (with adenovirus cultured from the cerebrospinal fluid), the skeletal muscle involvement (with a creatine phosphokinase of $8130 \mathrm{U} / \mathrm{l})$, and the myocarditis cannot be attributed to hypotension alone. We therefore believe that she had disseminated adenovirus infection producing a clinical picture identical to that of staphylococcal toxic shock syndrome.

Toxic shock-like syndrome has been described with several infectious agents, including staphylococcus, ${ }^{3}$ streptococcus, ${ }^{4}$ and pseudomonas ${ }^{5}$. The toxins which cause staphylococcal and streptococcal toxic shock syndrome have a common mode of action, binding to specific V $\beta$ bearing $T$ cells and stimulating $T$ cell proliferation and cytokine release. ${ }^{6}$ It is possible that similar immune events were induced by adrenovirus infection in this child.

We conclude that this case with multiorgan involvement producing a clinical picture of toxic shock syndrome was due to infection with adenovirus. We therefore recommend that clinicians consider adenovirus infection in the differential diagnosis of toxic shock syndrome in children.

We thank Dr R Dinwiddie, Dr P Habibi, and the staff of the intensive care unit, and the department of virology at the Hospital for Sick Children, Great Ormond Street, London.

1 Shands K, Schmid B, Dan D, et al. Toxic shock syndrome in menstruating women: association with tampon use and Staphylococcus aureus and clinical features in 52 cases. NEngl F Med 1980;303:1436-42.

2 Spencer M, Cherry J. Adenoviral infections. In: Fegin RD, Cherry JD, eds. Textbook of pediatric infectious diseases. 2nd Cherry JD, eds. Textbook of pediatric infectious diseas

3 Todd J, Fishaut M, Kapral F, Welch T. Toxic shock syndrome associated with phage-group-1 staphylococcus. Lancet 1978;ii:1116-8.

4 Torres-Martinez C, Mehta D, Butt A, Levin M. Streptococcus associated toxic shock. Arch Dis Child 1992;67:126-30.

5 Daman Willems C, Jones B, Matthew D. 1986 Pseudomonal toxic shock syndrome. Lancet 1986;ii:1218-9.

6 Marrack P, Kappler J. The staphylococcal enterotoxins and their relatives. Science 1990;248:705-11.

\title{
Accidental ingestion of 'Ecstasy' (3,4-methylenedioxymethylamphetamine)
}

\author{
A R Bedford Russell, R H Schwartz, S Dawling
}

\section{Department of Paediatrics, St Mary's Hospital, London A R Bedford Russell R H Schwartz \\ National Poisons Unit, Guy's and \\ Lewisham Trust, \\ London \\ S Dawling \\ Correspondence to: Dr A R Bedford Russell, Department of Child Health, St George's Hospital Medical School, \\ Cranmer Terrace,
London SW17 ORE. \\ Accepted 27 May 1992}

Table 1 Clinical features attributed to MDMA

Initial findings

Generalised shaking

Dilated pupils

Hypertonia

Writhing and jerking

movements

Within one hour

Convulsion

achyarrhythmia (70-170

beats/min)

Hypertension (maximum

$120 \mathrm{~mm} \mathrm{Hg}$ systolic pressure)

Fever (maximum temperature $38 \cdot 5^{\circ} \mathrm{C}$ per axilla)

\begin{abstract}
There is no report of the effects of 'Ecstasy' (3,4-methylenedioxymethylamphetamine) poisoning in childhood. The case of a 13 month old boy who ingested one capsule of Ecstasy is reported. Neurological and cardiovascular side effects predominated, which responded well to treatment with a chlormethiazole infusion.
\end{abstract}

\section{(Arch Dis Child 1992;67:1114-5)}

Recreational use of 'Ecstasy' or ' $E$ ' is common particularly within the confines of acid house parties. Chemically Ecstasy is 3,4methylenedioxymethylamphetamine (MDMA). MDMA is a psychoactive phenylisopropylamine, chemically related to both amphetamine-like stimulants and hallucinogens such as mescaline, and is reputedly safe. The usual dosage is $50-150 \mathrm{mg}$, and the duration of action is 4-6 hours. The drug reportedly induces a state of enhanced self awareness and ability to communicate, without distorting normal thought processes. ${ }^{1}$ Increasing use by young people has been documented, ${ }^{2}$ but our report and those of fatal or serious side effects in teenagers and adults $^{3-5}$ must caution against the belief that this drug is safe.

\section{Case report}

A 13 month old boy was admitted with a history of ingesting a capsule of Ecstasy found on the floor 30 minutes previously. He was in the care of his grandmother at her home while his mother was at work. His uncle, who was present, freely admitted to recreational use of the drug in this home where he also lived, but not on the evening in question.

The clinical features are summarised in table 1. The convulsion was unresponsive for 60 minutes to a total of $2.5 \mathrm{mg} / \mathrm{kg}$ diazepam and $0.4 \mathrm{mg} / \mathrm{kg}$ of haloperidol, both given intravenously. A chlormethiazole infusion $(10 \mathrm{mg} /$ $\mathrm{kg} /$ hour) was commenced and there was a dramatic response with both the convulsion and the cardiovascular instability resolving within 5-10 minutes. A further self limiting episode of hypertension $(180 / 70 \mathrm{~mm} \mathrm{Hg}$ ) and tachyarrhythmia ( 170 beats/min) occurred five hours after admission. All abnormal signs had resolved by seven hours so the chlormethiazole infusion rate was halved and finally stopped at 16 hours.

No haematological or biochemical abnormalities were observed. Results of toxicology are shown in table 2 .

The possibility of non-accidental ingestion of

Table 2 Toxicology on admission. Time represents interval since ingestion

\begin{tabular}{lll}
\hline Serum (at 90 minutes) & $\begin{array}{l}\text { MDMA } \\
\text { UDA }\end{array}$ & $\begin{array}{c}0 \cdot 7 \mathrm{mg} / 1 \\
<0 \cdot 1 \mathrm{mg} / 1 \\
\text { Detected } \\
\text { Detected }\end{array}$ \\
$\begin{array}{l}\text { MDMA } \\
\text { MDA }\end{array}$ & $\begin{array}{l}\text { Chlormethiazole } \\
\text { metabolites } \\
\text { Other basic or neutral } \\
\text { drugs }\end{array}$ & $\begin{array}{l}\text { Detected } \\
\text { Nil }\end{array}$ \\
\hline
\end{tabular}

